\title{
Pengaruh Profitabilitas, Leverage, Ukuran Perusahaan, Struktur Modal Dan Net Profit Margin Terhadap Nilai Perusahaan \\ (Studi Empiris Pada Perusahaan Consumer Goods yang Terdaftar di Bursa Efek Indonesia 2016-2018)
}

\author{
Dede Setiawan ${ }^{1}$, Irfan Rohanda ${ }^{2}$, Dirvi Surya Abbas ${ }^{3}$ \\ Fakultas Ekonomi dan Bisnis Universitas Muhammadiyah Tangerang ${ }^{1,2,3}$ \\ e-mail: ozandede13@gmail.com , irfanrohanda55@gmail.com (email korespondensi)
}

\begin{abstract}
Abstrak: Indonesia Penelitian ini bermaksud untuk menguji pengaruh profitabilitas, likuiditas, leverage, ukuran perusahaan, dan kebijakan dividen terhadap nilai perusahaan yang diukur dengan Tobin Q. Populasi dalam penelitian ini yaitu seluruh perusahaan Consumer Goods yang Terdaftar di Bursa Efek Indonesia 2016-2018. Maka, pengambilan sampel menggunakan system purposive sampling dan diperoleh 15 perusahaan. Metode yang digunakan adalah data sekunder berbentuk laporan keuangan tahunan perusahaan yang terdaftar di Bursa Efek Indonesia selama periode 2016-2018. Analisis ini menggunakan analisis regresi data panel. Hasil penelitian menunjukkan variabel profitabilitas, likuiditas dan ukuran perusahaan berpengaruh terhadap nilai perusahaan, sedangkan leverage, dan kebijakan dividen tidak berpengaruh terhadap nilai perusahaan.
\end{abstract}

Kata kunci: Profitabilitas, Likuiditas, Leverage, Ukuran Perusahaan, Kebijakan Dividen, Nilai Perusahaan.

Nilai perusahaan menggambarkan keadaan perusahaan di masa kini. Kenaikan nilai perusahaan merupakan pencapaian tinggi suatu perusahaan yang diinginkan oleh para pemiliknya. Dua produsen rokok ini mencatatkan pertumbuhan laba masing-masing $8,24 \%$ dan $24,48 \%$. Laba bersih ketiga emiten tersebut turun masing-masing sebesar $4,37 \%$ untuk UNVR, 0,51\% untuk MYOR, dan paling besar dialami GOOD mencapai 19,9\% .Menurunnya kinerja emiten subsektor makanan dan minuman juga sesuai dengan data Badan Pusat Statistik (BPS) mengenai pertumbuhan ekonomi sektor industri manufaktur, khususnya industri makanan dan minuman. Sumber:https://katadata.co.id Nilai saham sendiri ditentukan atas jumlah lembar saham yang dijumlah nilai pasar per lembar saham ditambah nilai hutang, dengan asumsi jika nilai hutang konstan maka secara langsung peningkatan nilai saham akan meningkatkan nilai perusahaan. Pengkajian ini menggunakan Tobin's Q sebagai variabel terikatnya untuk menghitung nilai perusahaan Faktor - faktor yang mempengaruhi nilai perusahaan yaitu Profitabilitas, Leverage, ukuran perusahaan, Struktur Modal dan Net Profit Margin. Profitabilitas merupakan kemampuan perusahaan menghasilkan laba yang akan menjadi dasar pembagian dividen, yaitu laba bersih perusahaan yang dibagikan pemegang saham ( Intan, 2019 ). Leverage Menurut (Hasibuan, AR, dan NP 2016) utang memiliki pengaruh baik maupun buruk terhadap perusahaan. Perusahaan harus menghasilkan keuntungan agar dapat menutupi kewajibannya. Ukuran perusahaan yang besar menunjukkan 
perusahaan mengalami perkembangan sehingga investor akan merespon positif dan nilai perusahaan akan meningkat. Pangsa pasar relatif menunjukkan daya saing perusahaan lebih tinggi dibanding pesaing utamanya. (Dani Gustian 2017) Struktur modal merupakan permasalahan yang penting bagi semua perusahaan, karena baik buruknya struktur modal akan memiliki efek yang langsung terhadap posisi keuangan perusahaan. Meythi (2012). Variabel kelima yang akan diteliti dalam hubungannya dengan nilai perusahaan adalah Net Profit Margin. Rasio ini sangat penting bagi perusahaan karena dapat mencerminkan strategi penetapan harga penjualan dan kemampuan perusahaan dalammengendalikan beban usaha sebagaimana dikemukakan oleh Sunyoto (2013: 121):

\section{METODE}

Berdasarkan jenis data dan analisis yang dipakai, pengkajian ini termasuk penelitian kuantitatif,yang mengacu pada nilai data berdasarkan angka. Penelitian ini sifatnya asosiatif kausal, yaitu penelitian yang mencari tahu tentang pengaruh sebab akibat kausal yang bertujuan untuk mengetahui pengaruh variabel bebas independen terhadap variabel terikat dependen (Sugiyono, 2012).

Perusahaan yang menjadi sampel adalah perusahaan-perusahaan manufaktur yang terdaftar dalam BEl (Bursa Efek Indonesia). metode pengambilan sampel yang dipakai ialah metode purposive sampling. Purposive sampling merupakan metode penentuan sampel dengan berbagai pertimbangan dan kriteria tertentu sesuai tujuan penelitian. Kriteria sampel yang dipakai dalam penelitian ini adalah sebagai berikut: Perusahaan manufaktur yang terdaftar di Bursa Efek Indonesia periode 2016-2018. Perusahaan menerbitkan laporan keuangan dalam satuan mata uang Rupiah sehingga perusahaan yang menerbitkan laporan keuangan dengan satuan mata uang Dollar akan dikeluarkan dari sampel.

Perusahaan manufaktur yang profit selama periode pengamatan 2016-2018. Perusahaan menerbitkan saham secara kontinyu selama periode pengamatan 2016 - 2018. Penelitian ini menggunakan dua jenis Variabel independen yaitu Profitabilitas, , Leverage, Ukuran Perusahaan, Struktur Modal dan Nett Profit Margin. Rasio harga saham terhadap nilai buku perusahaan atau Price Book Value (PBV), menunjukkan tingkat kemampuan perusahaan menciptakan nilai relatif terhadap jumlah modal yang diinvestasikan menurut Ariyanti (2019) rumus nilai perusahaan dengan variabel Tobin's $Q$. Data yang dipakai pada observasi ini adalah data kuantitatif. Hal ini dikarenakan datanya berupa angka- angka. Penelitian ini menggunakan data sekunder. Data sekunder adalah data yang diperoleh secara tidak langsung. Data tersebut berupa laporan keuangan yang diarsipkan atau dipublikasi. Analisis data dalam observasi yang dilakukan mengacu pada analisis kuantitatif yang merupakan pendekatan analisis dengan perhitungan matematika atau statistika. Analisis dalam penelitian ini menggunakan bantuan program Eviews 9 . 
Teknik analisis data untuk memecahkan masalah penelitian perlu memiliki dasar sebelum dipilih. Teknik analisis regresi data panel tepat digunakan jika data penelitian bersifat panel. Secara konsep, berdasarkan dimensi waktunya (time horizon), jenis data terbagi menjadi tiga yaitu cross section, time series dan panel. Statistik Deskriptif memberikan gambaran atau deskripsi suatu data yang dilihat dari nilai rata-rata (mean), standar deviasi, varian, maksimum, minimum, sum, range, kurtosis dan skewness (kemencengan distribusi), (Lubis et al., 2017) Teknik Pemilihan Model Regresi Data Panel terbagi menjadi 3 model yaiut uji chow, uji hausman, dan uji lagrange multiplier.

\begin{tabular}{lrrr} 
Tabel 1 uji Chow & & & \\
Redundant Fixed Effects Tests \\
Equation: EQ01 \\
Test cross-section fixed effects \\
\hline \hline Effects Test & & & \\
\hline \hline Cross-section F & Statistic & d.f & Prob. \\
Cross-section Chi-square & 1.040875 & $(14,25)$ & 0.4488 \\
& 20.666346 & 14 & 0.1105
\end{tabular}

Uji Chow untuk membandingkan antara model common effect dan fixed effect model untuk selanjutnya dipilih sebagai model-model regresi panel yang lebih baik. Chow test dalam penelitian ini menggunakan program Eviews 9.0 (Darmawan \& Lifatin, 2019). Berdasarkan hasil perhitungan diatas nilai Probabilitas Cross- section F dan Cross-section chi- quare $>\alpha$ $(0,05)$, maka dapat disimpulkan bahwa Common Efect Model (CEM) lebih layak digunakan dibandingkan Fixed Effect Model (FEM).

Tabel 2 Hausman

Correlated Random Effects - Hausman Test

Equation: EQ01

Test cross-section random effects

\begin{tabular}{lrrr}
\hline \hline Test Summary & Chi-Sq. Statistic & Chi-Sq. d.f & Prob. \\
\hline \hline Cross-section random & 9.607722 & 5 & 0.0871 \\
\hline \hline
\end{tabular}

Uji hausman untuk membandingkan dan memilih antara fixed effect model dan random effect model dalam menentukan model regresi panel yang terbaik. Hausman test dalam penelitian ini menggunakan program eviews 9.0 (Darmawan \& Lifatin, 2019). Berdasarkan hasil perhitungan diatas nilai Probabilitas (Prob.) Cross-section random $>a(0,05)$, maka dapat disimpulkan bahwa Random Effect Model (REM) lebih layak digunakan dibandingkan Fixed Effect Model (FEM).

Tabel 3 Uji Lagranga Multiper 


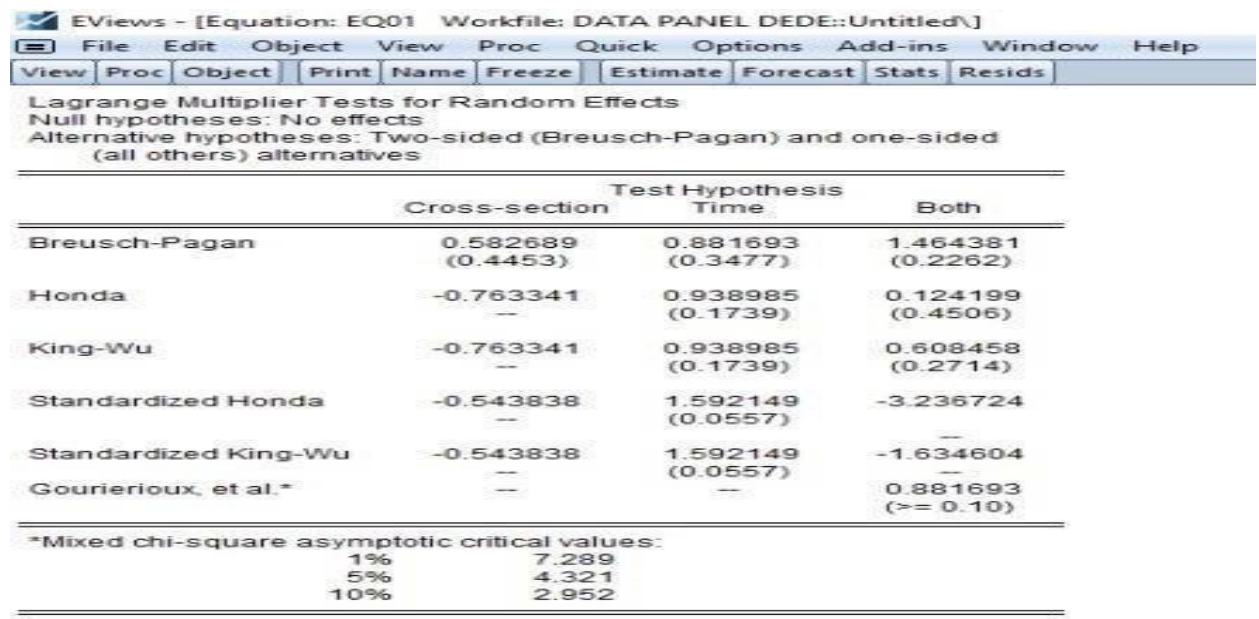

Uji lagranga multiper (LM) digunakan untuk memilih model data panel yang terbaik antara random effect dan common effect model

(Darmawan \& Lifatin, 2019). Berdasarkan hasil perhitungan diatas nilai Probabilitas Cross- section Breausch-pagan $>\alpha(0,05)$, maka dapat disimpulkan bahwa Common Effect Model (CEM) lebih layak digunakan dibandingkan Random Effect Model (REM).

\section{HASIL}

\section{a. Uji Chow}

\section{Redundant Fixed Effects Tests \\ Equation: EQ01 \\ Test cross-section fixed effects}

\begin{tabular}{lrrr}
\hline \hline Effects Test & Statistic & d.f. & Prob. \\
\hline \hline Cross-section $F$ & 1.040875 & $(14,25)$ & 0.4488 \\
Cross-section Chi-square & 20.666346 & 14 & 0.1105
\end{tabular}

Berdasarkan hasil perhitungan diatas nilai Probabilitas Cross- section F dan Cross-section chi- quare $>\alpha(0,05)$, maka dapat disimpulkan bahwa Common Efect Model (CEM) lebih layak digunakan dibandingkan Fixed Effect Model (FEM).

\section{b. Uji Hausman}

Correlated Random Effects - Hausman Test

Equation: EQ01

Test cross-section random effects

\begin{tabular}{lrrr}
\hline \hline Test Summary & Chi-Sq. Statistic & Chi-Sq. d.f. & Prob. \\
\hline \hline Cross-section random & 9.607722 & 5 & 0.0871
\end{tabular}

Berdasarkan hasil perhitungan diatas nilai Probabilitas (Prob.) Crosssection random > a $(0,05)$, maka dapat disimpulkan bahwa Random Effect Model (REM) lebih layak digunakan dibandingkan Fixed Effect Model (FEM). 


\section{c. Uji Lagrange Multipiler}

I. EViews - [Equation: EQ01 Workfile: DATA PANEL DEDE: Untitled]]

$\Xi$ File Edit Object View Proc Quick Options Add-ins Window Help

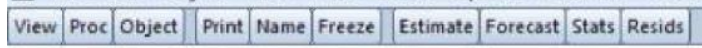

Lagrange Multiplier Tests for Random Effects

Null hypotheses: No effects

Alternative hypotheses: Two-sided (Breusch-Pagan) and one-sided (all others) alternatives

\begin{tabular}{lccc}
\hline \hline & \multicolumn{3}{c}{ Test Hypothesis } \\
& Cross-section & Time & Both \\
\hline \hline Breusch-Pagan & 0.582689 & 0.881693 & 1.464381 \\
& $(0.4453)$ & $(0.3477)$ & $(0.2262)$ \\
Honda & -0.763341 & 0.938985 & 0.124199 \\
& - & $(0.1739)$ & $(0.4506)$ \\
King-Wu & -0.763341 & 0.938985 & 0.608458 \\
& - & $(0.1739)$ & $(0.2714)$ \\
Standardized Honda & -0.543838 & 1.592149 & -3.236724 \\
& - & $(0.0557)$ & - \\
Standardized King-Wu & -0.543838 & 1.592149 & -1.634604 \\
& - & $(0.0557)$ & - \\
Gourierioux, et al. ${ }^{*}$ & - & - & 0.881693 \\
& & & $(\succ=0.10)$ \\
\hline \hline
\end{tabular}

"Mixed chi-square asymptotic critical values

$\begin{array}{rr}1 \% & 7.289 \\ 5 \% & 4.321 \\ 10 \% & 2.952\end{array}$

Berdasarkan hasil perhitungan diatas nilai Probabilitas Cross- section Breausch-pagan $>\alpha(0,05)$, maka dapat disimpulkan bahwa Common Effect Model (CEM) lebih layak digunakan dibandingkan Random Effect Model (REM).

\section{Data Panel Yang Digunakan}

\begin{tabular}{c|l|c|c} 
No & \multicolumn{1}{|c|}{ Metode } & Pengujian & Hasil \\
\hline 1 & Uji Chow & CEM VS FEM & CEM \\
\hline 2 & Uji Hausman & REM VS FEM & REM \\
\hline 3 & Uji Lagrange Multiplier & CEM VS REM & CEM
\end{tabular}

Berdasarkan hasil ke tiga pengujian yang sudah dilakukan maka dapat disimpulkan bahwa Model Regresi Data Panel yang akan digunakan dalam Uji Hipotesis dan persamaan Regresi Data Panel adalah model Common Effect Model (CEM).

\section{a. Uji Multikolinieritas}

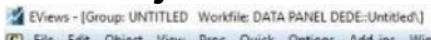

(G) File Edo Object View Proc Quick Optons Add-ins Window Help

command

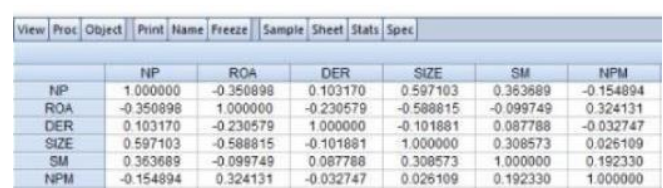

Berdasarkan table diatas, dapat dilihat tidak terdapat variable indenpenden yang memiliki nilai lebih dari 0,8 sehingga dapat disimpulkan tidakterjadi multikolinieritas dalam model regresi. 


\section{b. Uji Heteroskedastisitas}

1 EViews - [Equation: EQ01 Workdie: DATA PANELtuntitied]

$\square$ File Edit Object View Proc Quick Options Add-ins Window Help

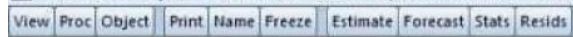

Residual Cross-Section Dependence Test

Null hypothesis: No coss-section dependence (correlation) in residuals

Equation: EQ01

Periods included 3

Cross-sections included 15

Total panel observations: 45

Note: non-zero cross-5ection means detected in dats

Cross-section means were removed during computation of correlations

\begin{tabular}{llll}
\hline \multicolumn{1}{c}{ Test } & Statistic & d.t. & Prob. \\
\hline \hline Breusch-Pagan LM & 148.1120 & 105 & 0.3586 \\
Pesaran scaled LM & 1939914 & & 0.0524 \\
Pesaran CD & 0.941699 & & 0.3463 \\
\hline
\end{tabular}

Berdasarkan table diatas, dapat dilihat nilai Breusch-Pagan LM sebesar $0.3586>a(0,05)$, maka dapat simpulkan penelitian ini bebas Heteroskedastisitas maka layak untuk dilanjutkan.

\section{Uji Kelayakan Model (F)}

\begin{tabular}{lrll}
\hline \hline R-squared & 0.472110 & Mean dependent var & 2.7651 \\
Adjusted R-squared & 0.404432 & S.D. dependent var & 2.3123 \\
S.E. of regression & 1.784500 & Akaike info criterion & 4.1197 \\
Sum squared resid & 124.1931 & Schwarz criterion & 4.3606 \\
Log likelihood & -86.69368 & Hannan-Quinn criter & 4.2095 \\
F-statistic & 6.975802 & Durbin-Watson stat & 1.9805 \\
Prob(F-statistic) & 0.000097 & & \\
\hline
\end{tabular}

Berdasarkan hasil tabel Fixed Effect Model yang ditampilkan pada tabel diatas menunjukan bahwa nilai $\mathrm{F}$ statistic adalah 6.975802 lebih besar dari pada nilai $F$ Tabel yaitu 2.85, dan nilai prob statistic 0.000097 lebih kecil dari pada 0.05 maka dapat disimpulkan bahwa dalam uji $F$ statistic dalam penelitian ini berpengaruh, SIZE,NPM secara bersama-sama memiliki pengaruh terhadap Nilai Perusahaan.

\section{c. Uji R2(Koefisien Determinasi)}

\begin{tabular}{lrll}
\hline \hline R-squared & 0.472110 & Mean dependent var & 2.765142 \\
Adjusted R-squared & 0.404432 & S.D. dependent var & 2.312334 \\
S.E. of regression & 1.784500 & Akaike info criterion & 4.119719 \\
Sum squared resid & 124.1931 & Schwarz criterion & 4.360607 \\
Log likelihood & -86.69368 & Hannan-Quinn criter. & 4.209520 \\
F-statistic & 6.975802 & Durbin-Watson stat & 1.980541 \\
Prob(F-statistic) & 0.000097 & & \\
\hline \hline
\end{tabular}

Pada tabel diatas menunjukkan bahwa nilai dalam uji koefisien determinasi nilai adjusted R-Squared yaitu 0.404432 yang artinya bahwa variable perubahan naik turunnya nilai perusahaan dapat dijelaskan oleh ROA, DER, Ukuran Perusahaan, Struktur Modal dan NPM sebesar $40.44 \%$ sementara sisanya dijelaskan oleh variable- variabel lain yang tidak diteliti dalam penelitian ini. 
d. Uji T Parsial

\begin{tabular}{crrrr}
\hline \hline Variable & Coefficient & Std. Error & t-Statistic & Prob. \\
\hline \hline C & -62.66472 & 16.21447 & -3.864741 & 0.0004 \\
ROA & 0.462268 & 0.396720 & 1.165223 & 0.2510 \\
DER & 0.565784 & 0.379925 & 1.489200 & 0.1445 \\
SIZE & 2.433567 & 0.598263 & 4.067718 & 0.0002 \\
SM & 0.345628 & 0.207563 & 1.665174 & 0.1039 \\
NPM & -0.634873 & 0.305758 & -2.076393 & 0.0445 \\
\hline
\end{tabular}

Dalam uji T Statistik yang berpengaruh adalah variabel SIZE dan NPM, karena nilai Prob size 0.0002 lebih kecil dari 0.05, dan T Statistik nya yaitu 4.067718 lebih besar dari T table yaitu 2.02269, sedangkan untuk variabel NPM nilai prob NPM 0.0445 lebih kecil dari pada 0.05 , dan T statistic nya2.076393 lebih besar dari T table yaitu 2.02269 yang artinya berpengaruh negatif. Maka dapat disimpulkan dalam penelitian ini yang berpengaruh adalah variabel size berpengaruh positif dan variabel NPM berpengaruh negative

\section{KESIMPULAN}

Dari hasil analisis data dan pembahasan yang telah diuraikan pada bab sebelumnya, bahwa penelitian ini dilakukan untuk mengetahui pengaruh profitabilitas, leverage, ukuran perusahaan,struktur modal dan Net profit perusahaan(NPM) terhadap nilai perusahaan. Maka dapat diambil kesimpulan dari hasil analisis regresi berganda sebagai berikut:

1. Profitabilitas tidak berpengaruh terhadap nilai perusahaan, yang ditunjukkan dengan nilai signifikansiprofitabilitas terhadap nilai perusahaan diatas 0,05 yaitu sebesar 0,2510 .

2. Leverage tidak berpengaruh terhadap nilai perusahaan, yang ditunjukkan dengan nilai signifikansi likuiditas terhadap nilai perusahaan diatas 0,05 yaitu sebesar 0,1445 .

3. Ukuran perusahaan berpengaruh terhadap nilai perusahaan, yang ditunjukkan dengan nilai signifikansi ukuran perusahaan terhadap nilai perusahaan dibawah 0,05 yaitu sebesar

0,0002 .

4. Struktur modal tidak berpengaruh terhadap nilai perusahaan, yang ditunjukkan dengan nilai signifikansi struktur modal terhadap nilai perusahaan diatas 0,05 yaitu sebesar 0,1039.

5. Net profit perusahaan (NPM) berpengaruh terhadap nilai perusahaan, yang ditunjukkan dengan nilai signifikansi Net profit perusahaan terhadap nilai perusahaan dibawah 0,05 yaitu sebesar 0,0445 .

\section{DAFTAR PUSTAKA}

Dewi Rahmawati, Topowijono, Sri Sulasmiyati. PENGARUH UKURAN PERUSAHAAN, PROFITABILITAS, STRUKTUR MODAL, DAN KEPUTUSAN INVESTASI TERHADAP NILAI PERUSAHAAN (Studi pada Perusahaan Sektor Properti, Real Estate, dan Building 
Construction yang Terdaftar di Bursa Efek Indonesia (BEI) Periode 2010- 2013). J Adm. 2015;23(2):1-7.

Brealey RA, Myers stewart C, Marcus AJ. Dasar-dasar manajemen keuangan perusahaan. In: Erlangga. ; 2007:Jilid 2.

Denny Kurnia. Analisis Signifikansi Leverage Dan Kebijakan Deviden Terhadap Nilai Perusahaan. J Account. 2017;4(2):12-21.

Denziana A, Monica W. Analisis Ukuran Perusahaan dan Profitabilitas Terhadap Nilai Perusahaan (Studi Empiris Pada Perusahaan Yang Tergolong LQ45 di BEI Periode 2011- 2014). J Akunt dan Keuang. 2016;7(2):2087-2054. doi:10.5151/cidi2017-060

Eka Indriyani. Pengaruh Ukuran Perusahaan dan Profitabilitas Terhadap Nilai Perusahaan. J Ilmu Akunt. 2017;10(2):333-348. doi:10.15408/akt.v10i2.4649

Emilia Gustini. PENGARUH KEBIJAKAN DIVIDEN DAN KEBIJAKAN HUTANG TERHADAP NILAI PERUSAHAAN (STUDI EMPIRIS PERUSAHAAN BUMN YANG TERDAFTAR DI BURSA EFEK INDONESIA). J IIm Ekon Glob MASA KINI. 2017;8(02):5. doi:10.30998/jabe.v3i3.1769

Hardian AP, Asyik NF. Kinerja Keuangan dan ukuran perusahaan terhadap Amalia Dewi Rahmawati, Topowijono, Sri Sulasmiyati. PENGARUH UKURAN PERUSAHAAN, PROFITABILITAS, STRUKTUR MODAL, DAN KEPUTUSAN INVESTASI TERHADAP NILAI PERUSAHAAN (Studi pada Perusahaan Sektor Properti, Real Estate, dan Building Construction yang Terdaftar di Bursa Efek Indonesia (BEI) Periode 2010-2013). J Adm. 2015;23(2):1-7.

Anggraeni IGMAKD. PENGARUH DEBTTOEQUITYRATIO(DER), DEBTTOTOTALASSET(DTA), DIVIDEN TUNAI, DAN UKURAN PERUSAHAAN TERHADAP NILAI 20 PERUSAHAAN (Perusahaan Manufaktur Sektor Barang Konsumsi Yang Terdaftar Di Bursa Efek Indonesia Periode 2011-2014). J Akunt dan Keuang. 2015;4(1):100120. doi:10.1145/3132847.3132886

Brealey RA, Myers stewart C, Marcus AJ. Dasar-dasar manajemen keuangan perusahaan. In: Erlangga. ; 2007:Jilid 2.

Denny Kurnia. Analisis Signifikansi Leverage Dan Kebijakan Deviden Terhadap Nilai Perusahaan. J Account. 2017;4(2):12-21.

Denziana A, Monica W. Analisis Ukuran Perusahaan dan Profitabilitas Terhadap Nilai Perusahaan (Studi Empiris Pada Perusahaan Yang Tergolong LQ45 di BEI Periode 2011-2014). J Akunt dan Keuang. 2016;7(2):2087-2054. doi:10.5151/cidi2017-060

Eka Indriyani. Pengaruh Ukuran Perusahaan dan Profitabilitas Terhadap Nilai Perusahaan. J Ilmu Akunt. 2017;10(2):333- 348. doi:10.15408/akt.v10i2.4649

Hasibuan V, Dzulkirom AR M, Wi Endang NP N. PENGARUH LEVERAGE DAN PROFITABILITAS TERHADAP NILAI 